\title{
A Proposed Mechanism of Snowstorm Mesojet over Japan under the Influence of the Winter Monsoon
}

\author{
By T. Fujita \\ The University of Chicago \\ and $K$. Tsuchiya \\ Japan Meteorological Agency \\ (Manuscript received 5 September 1966)
}

\begin{abstract}
While Tsuchiya and Fujita (1966) were investigating mesoscale features of winter monsoon clouds over Japan by using satellite photographs and radiation data, a mesoscale upper-air disturbance was found to exist over the region of monsoon snowfall on the windward side of Hokkaido and northern Honshu as they block the strong northwesterly monsoon. A relatively dense upper-air network with an average spacing of $200 \mathrm{~km}$ (120 miles) permitted us to analyze mesosynoptically the vertical structure of the upper-air mesosystem. The system was characterized by a cold dome directly above which warm dry air descended from an eroded tropopause. Analyses of 1963 and 1964 data revealed that the upper-air mesosystem stays more or less over the regions of monsoon snowfall while high-level winds blow through it within a few hours. To explain the formation and development of this upper-air mesosystem, a mechanism of mesoscale jet stream called "snowstorm mesojet" has been proposed.
\end{abstract}

\section{Introduction}

The islands of Japan are located where the largest continent and ocean meet. In winter, especially when the northwesterly monsoon prevails, the low-level flow leaving Siberia undergoes rapid modification before reaching the islands. The northwest coast of these islands is washed by the warm Tsushima current, which cools from a temperature of about $13 \mathrm{C}$ to $7 \mathrm{C}$ as it travels northeastward.

If the Japanese islands were flat, the moisture stored in the lower portion of the cold air would be deposited on them probably in the form of such "lake snow" as is usually seen on the leeward side of the Great Lakes of the United States, where light to moderate snow continues for hours or sometimes for several days.

The central mountains of Japan range between 1000 and $3000 \mathrm{~m}$ with a few low gaps which permit snow clouds to leak through into the Pacific Ocean. By and large, the mountains block low-level flow, thus forcing the atmosphere to unload its moisture as it moves over the mountains. From one day to the next, however, the amount of snowfall varies according to the dynamical and thermodynamical characteristics of the monsoon.

In his study of the band structure of snowfall over the low, flat Ishikari Plain in Hokkaido, Higuchi (1962) pointed out that a large curvature of wind-speed profile plotted against the altitude is closely related to the occurrence of snowfall bands over the plain. According to his study, the top of the curved profile is located at about a 3- to 4-km level, usually topped by a temperature inversion or a stable layer.

Based upon the empirical rule that heavy snowfall is closely related to the trajectory of the middle-level, cold cut-off low over the Sea of Japan, Fukuda (1960) and Matsumoto et al (1965) studied the structure of cut-off lows. It is generally agreed that the dome of extremely cold air, often reaching the $400-\mathrm{mb}$ surface, acquires a very large temperature lapse rate during its trajectory over the warm waters of the Sea of Japan. A cold vortex about $1500 \mathrm{~km}$ across, studied by Matsumoto 
and Ninomiya (1965), moved so steadily eastward that the time-to-space conversion technique and the assumption of adiabatic motion permitted them to compute the vertical circulation of the air at the 500 - and $300-\mathrm{mb}$ surfaces to the east and west of the dome.

Mesoscale pressure disturbances associated with the cold vortices over the Sea of Japan were also investigated by Matsumoto and Ninomiya (1965). They found that a wave of pressure anomaly from 2.5-hr running means propagates from the Sea of Japan inland at the rate of some $90 \mathrm{~km} / \mathrm{hr}$. In order to justify such a high rate of speed, an attempt was made to explain the phenomenon as an internal gravity wave moving eastward at the top of the cold dome which was also moving eastward over the region of the pressureanomaly wave.

To be discussed in this paper is a stationary mesoscale meteorological system extending from the surface to beyond the tropopause over the region of snowfall on the windward side of the Japanese Islands under the influence of the winter monsoon. The mesoscale system moved rather slowly along with the overall region of snowfall which did not traverse the islands as traveling synoptic-scale systems usually do. The snowfall region under discussion is characterized by a horizontal dimension of about $1000 \mathrm{~km}$ along the coast of the Sea of Japan. Despite the fact that the surface temperatures do not show significant cooling over the snowfall region, a mesoscale dome of cold air becomes noticeable as the height increases, thus resulting in a significant cold dome between the $700-$ and $500-\mathrm{mb}$ surfaces, with maximum intensity at about 600 mb. Above the $300-\mathrm{mb}$ surface the dome changes into a warm one extending upward even beyond the tropopause, which is normally low at the time of the winter monsoon.

\section{Upper-air observation network}

The regular radiosonde network of Japan (Fig. 1) covers the entire nation with an average spacing of $250 \mathrm{~km}(150 \mathrm{mi})$, more dense though less extensive than that of the United States. Two stations, Misawa (580) and Hamamatsu (681), are operated by the Japanese Civil Defense Unit, thus making the network over the northeastern half of Japan much

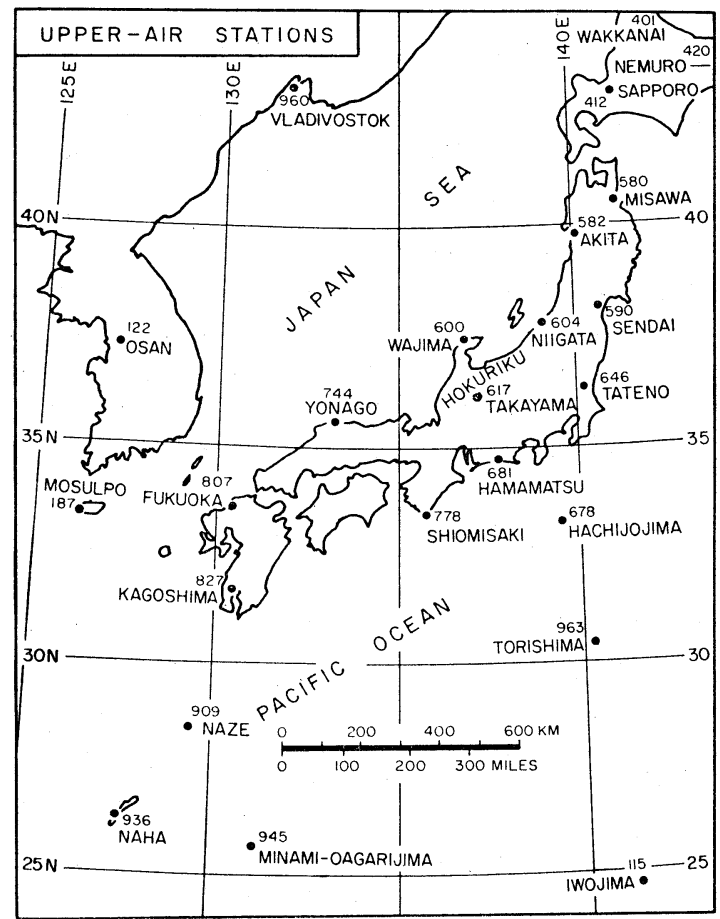

Fig. 1. Distribution of upper-air stations in Japan and the western Pacific.

denser than that over the rest of the nation.

For the purpose of investigating heavy snow situations during mid-winter monsoons, the Japan Meteorological Agency operated two additional upper-air stations, Niigata (604) and Takayama (617), during the periods of its "Project Heavy Snowfall,"* thus making a total of 13 radiosonde stations in an area of northeastern Japan smaller than the state of California. Shown in Fig. 1 is the distribution of the 24 stations used in this study, i.e., 1 Russian, 2 U.S., 2 Korean, and 19 Japanese.

Both temperature and wind data from the 13 Japanese stations located in northeastern Japan were found to be of excellent quality, since they are checked data that include a large number of significant points. A mesoscale upper-air analysis could never have been

* “Project Heavy Snowfall" was operated during the periods February 16-21, 1962 (I); January 16-26, 1963 (II); and January 20-27, 1964 (III). Data from each period are published in Japanese, as follows: (I) Preliminary Observation Data for Analyses of Heavy Snowfall due to Hokuriku Fronts. Vol. 1 for surface and Vol. 2 for upper-air data. Published by Tokyo District Met. Office, J.M.A. (II) and (III) Data on Special Observations of Heavy Snowfall in Hokuriku. Published by Met. Res. Inst., J.M.A. 
attempted without these accurate data collected by a dense network of upper-air stations.

\section{Persistence of an upper-air mesosystem over the region of heavy snowstorms}

As a first step in revealing the structure of the upper-air mesosystem found over the region of heavy snowstorms, it is necessary to show its existence by the careful analysis of synoptic charts. These charts will also help in understanding its horizontal scale as well as its persistence in connection with the patterns of monsoon snowfall along the Japan Sea side of the Japanese Islands.

In view of the fact that monsoon snowfall usually continues for days with varying intensity, a series of synoptic analyses was made for every 12-hr interval. Fig. 2 through 5 include surface, $600-\mathrm{mb}$, and $300-\mathrm{mb}$ charts covering the period from $12 Z$ January 19, 1964 to $00 Z$ January 21,1964 . The area of analysis is identical to that of Fig. 1 so that geographic locations and horizontal dimensions can be determined easily.
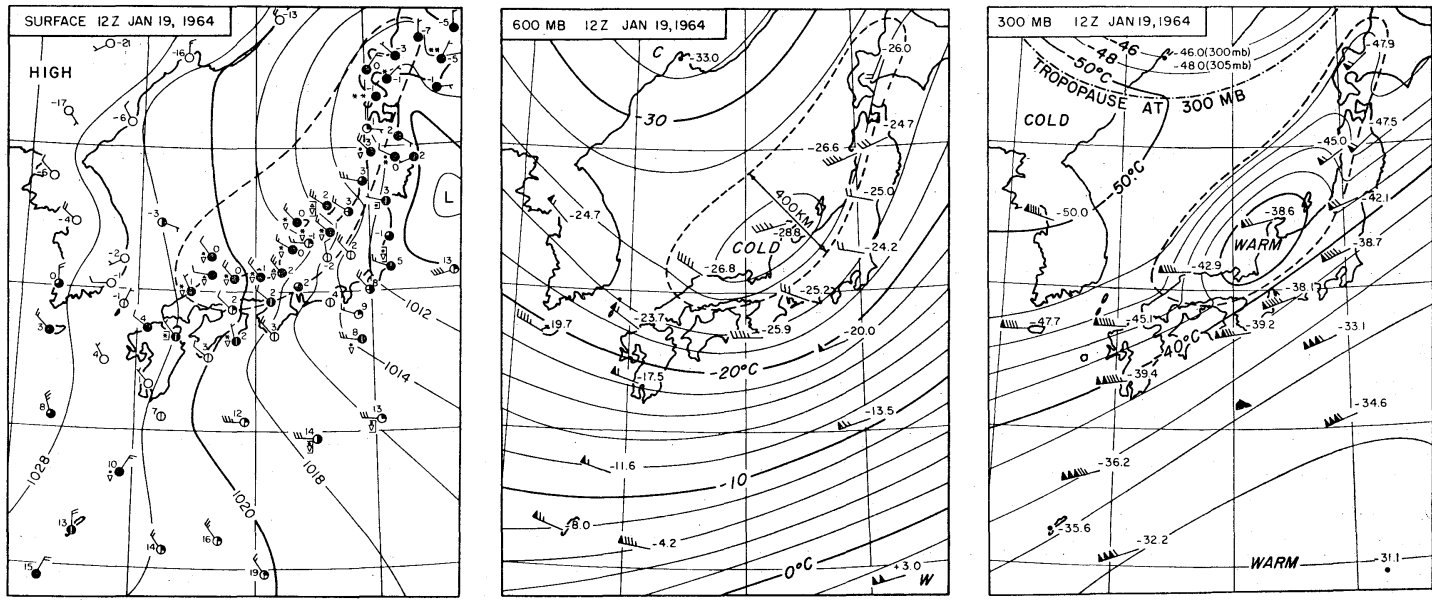

Fig. 2. Surface $600-\mathrm{mb}$ and $300-\mathrm{mb}$ charts at $12 Z$, January 19, 1964. The region of monsoon snowfall is indicated by a dashed line. Surface map, including station weather and temperatures in degrees Centigrade, is contoured with isobars at 2 - $\mathrm{mb}$ intervals. Both the 300- and the 600-mb charts are contoured with isotherms for every $2 \mathrm{C}$. Winds aloft and upper-air temperatures were plotted at each station despite the fact the radiosonde balloons may have drifted as far as 100 $\mathrm{km}$ downwind. Note that the tropopause over Vladivostok at this time was below the $300 \mathrm{mb}$ surface.

The surface maps were made to determine the low-level flow patterns and the regions of snowfall. They include types of precipitation and air temperature reported by each station. $600-\mathrm{mb}$ pressure surfaces were chosen as the most effective to show the temperature field near the mid-level of the mesoscale cold dome over the region of snowfall. $300-\mathrm{mb}$ charts, on the other hand, represent warming which takes place in a mesoscale area directly above the cold dome. All three charts thus analyzed include heavy dashed lines designating the mean boundary of the mesosystem below 300 mb. Note that the three boundaries in each figure are identical.

When the series of surface maps is examined, the intense monsoon snowfall at $12 Z$, January
19,1964 is seen centered near Wajima (600), diminishing toward Yonago (744) and Akita (582). Twelve hours later the snowfall area shifted slightly toward the northeast, centering around Niigata (604). Further northeast movement took place by $12 Z$, January 20, 1964 when the intensity center is seen near Akita (582). Such a movement of the snowfall area is rather common during the winter monsoon period. Within the next 12 hours, however, the center diffused as it moved back toward Niigata (604).

Of interest is the movement of the cold areas indicated by the isotherms contoured at $2 \mathrm{C}$ intervals on the 600 -mb surface. The first $600-\mathrm{mb}$ chart at 12Z, January 19, 1964 reveals a cold spot of about $-29 \mathrm{C}$, to the southwest of Wajima (600), surrounded by an environ- 
ment at least $4 \mathrm{C}$ warmer. At this stage of a mesoscale cold-dome development, it is rather difficult to separate the dome from a much larger, synoptic-scale dome to the northwest similar to that studied by Matsumoto and Ninomiya (1965a). Normally, the mesoscale dome under discussion covers no more than one-tenth of the area occupied by a synopticscale dome. It should be pointed out that the center of the $300-\mathrm{mb}$ warm area, with an air temperature of $-38 \mathrm{C}$, is located directly above the coldest spot on the $600-\mathrm{mb}$ surface. When the environmental temperature of the mesosystem is subtracted from $-38 \mathrm{C}$, the excess is seen to be about $6 \mathrm{C}$.

A remarkable coincidence in the locations of the heavy snowfall area and the centers of the cold and warm areas is seen in Fig. 3, including charts at $00 \mathrm{Z}$, January 20,1964 . The areas $5 \mathrm{C}$ colder and $10 \mathrm{C}$ warmer than the environment are quite significant in the upperair charts. Another interesting feature is that the $50-\mathrm{kt}$ winds would take only about five hours to blow through the system, thus allowing no time for heat exchange between air parcels and their environment in order to permit a constant pressure flow. An expected semi-isentropic flow will let winds near the 600 mb surface pass through the mesosystem following a mound-shaped isentrope. Near the 300-mb surface, winds will follow a depressed isentrope, since a higher temperature inside the high-level mesosystem results in a considerable depression of the isentropic surface.
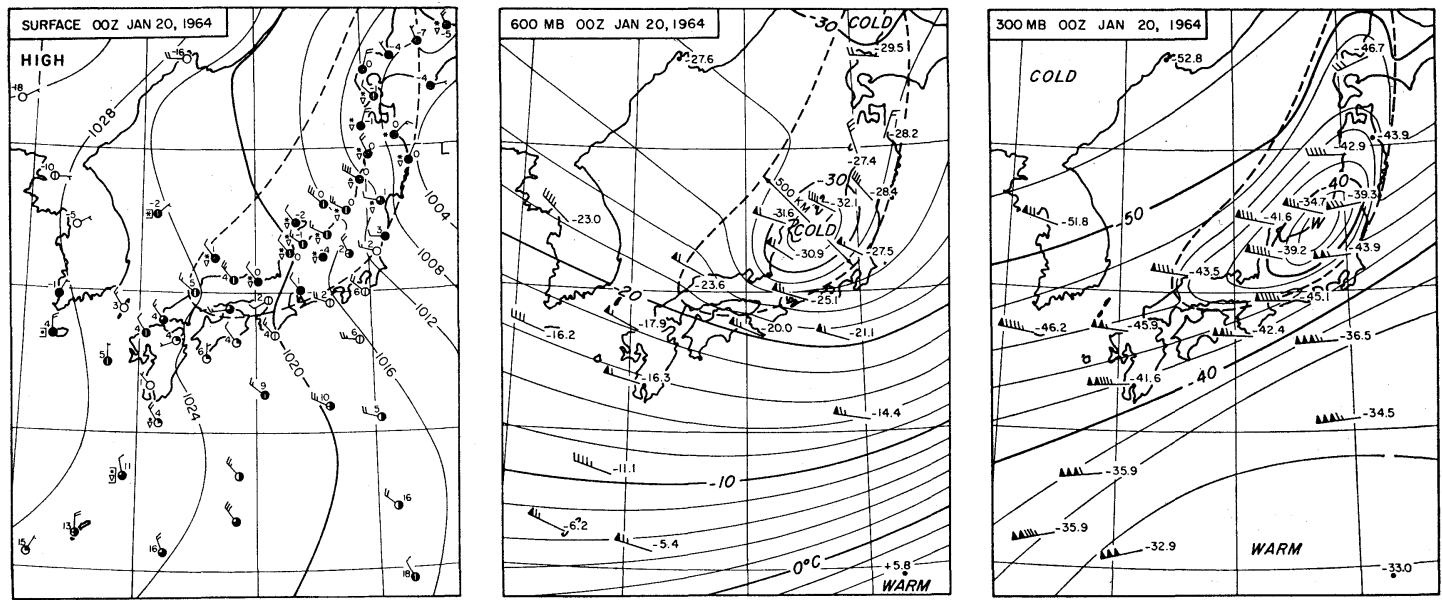

Fig. 3. Surface, $600-\mathrm{mb}$ and $300-\mathrm{mb}$ charts at $00 Z$, January 20, 1964. The region of monsoon snowfall is indicated by a dashed line. A $6.8 \mathrm{C}$ rise in Vladivostok's temperature at the 300 -mb surface during the past $12 \mathrm{hr}$ was due mainly to the lifting of the tropopause.

Even though the surface pressure gradient decreased during the $12-\mathrm{hr}$ period ending at $12 Z$ January 20, 1964, an elongated mid-level cold dome topped by a high-level warm area existed over the region of snowfall extending north-northeast from Wajima (600) to Sapporo (412). The excess and deficit temperatures of $5 \mathrm{C}$ are still recognizable at both high and low levels. It is of particular interest that Niigata (604), showing a quite low temperature of $-28.5 \mathrm{C}$ on the $600-\mathrm{mb}$ surface, changes into the warmest, $-42.4 \mathrm{C}$, at the $300-\mathrm{mb}$ surface, while surrounding stations outside the highlevel mesosystem report lower than $-46.6 \mathrm{C}$.

The last charts for $00 Z$, January 21, 1964
(Fig. 4) reveal a condition in which the northwesterly monsoon, estimated by the gradient of sea-level isobars crossing northern Japan, has weakened considerably; nevertheless, a mesosystem still exists over the region of monsoon snowfall. At $300-\mathrm{mb}$, especially, the warm area is so pronounced that a "hot spot" is seen over Niigata (604). The width of the mesosystem in the direction of the $300-\mathrm{mb}$ winds is only about $400-\mathrm{km}$ (250 mi), while the wind speed is as high as $100 \mathrm{kt}$. The winds are blowing through the system in about 2 $\mathrm{hr}$, yet the whole mesosystem, including highand low-level disturbances, is not advected toward the Pacific Ocean. 

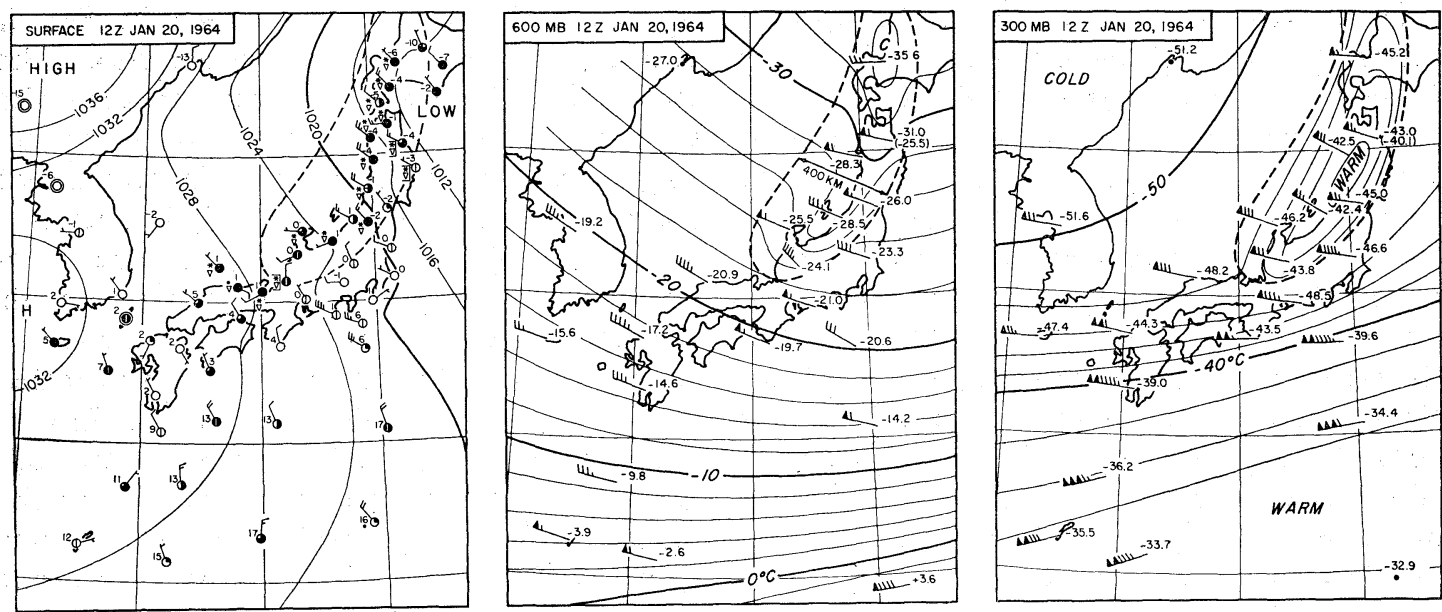

Fig. 4. Surface, $600-\mathrm{mb}$ and $300-\mathrm{mb}$ charts at $12 \mathrm{Z}$, January 20,1964 . The region of monsoon snowfall is indicated by a dashed line.
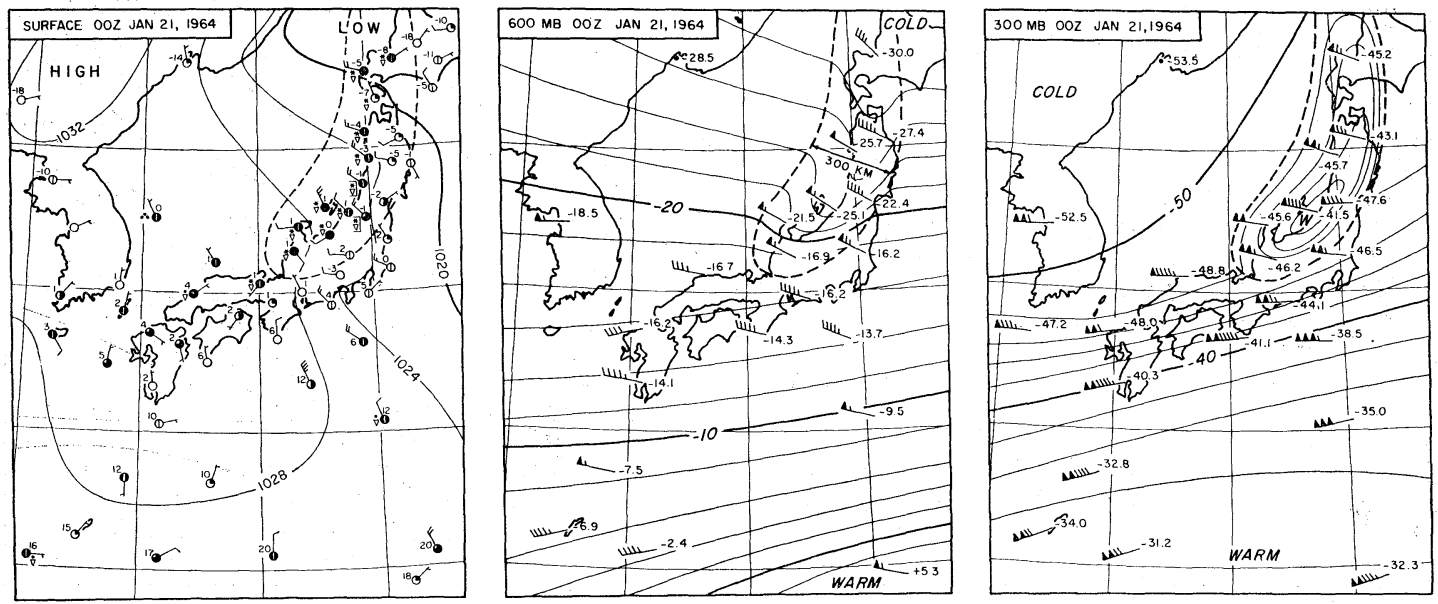

Fig. 5. Surface, $600-\mathrm{mb}$ and $300-\mathrm{mb}$ charts at $00 \mathrm{Z}$, January 21,1964 . The region of monsoon snowfall is indicated by a dashed line.

As a result of these analyses, it may be concluded that the mesoscale upper-air disturbance located over the region of wintermonsoon snowfall in Japan is extremely persistent. The mesosystem does move slightly with the snowfall region, but it is not steered away from the Japan Sea side of the Japanese Islands even though high-level winds blow through it continuously. This evidence leads us to the conclusion that the dynamical effect of the mountains, coupled with the release of latent heat along the Japan Sea side, plays an important role in the initiation and maintenance of a mesoscale system that extends practically from the surface to the tropopause or even beyond. Detailed discussion of the cause and effect appears in the following sections.

\section{Vertical structure of fhe upper-air meso- system}

It has been shown that a mesoscale cold dome over the region of heavy monsoon snowfall is topped by a high-level warm area. The vertical extent of such upper-air disturbances will be investigated with the use of constantpressure and vertical cross-section charts.

A series of six constant-pressure charts (Fig. 6) at 00Z, January 20, 1964 was selected for detailed examination, since this map time is very close to the exposure times of satellite photographs studied by Tsuchiya and Fujita 


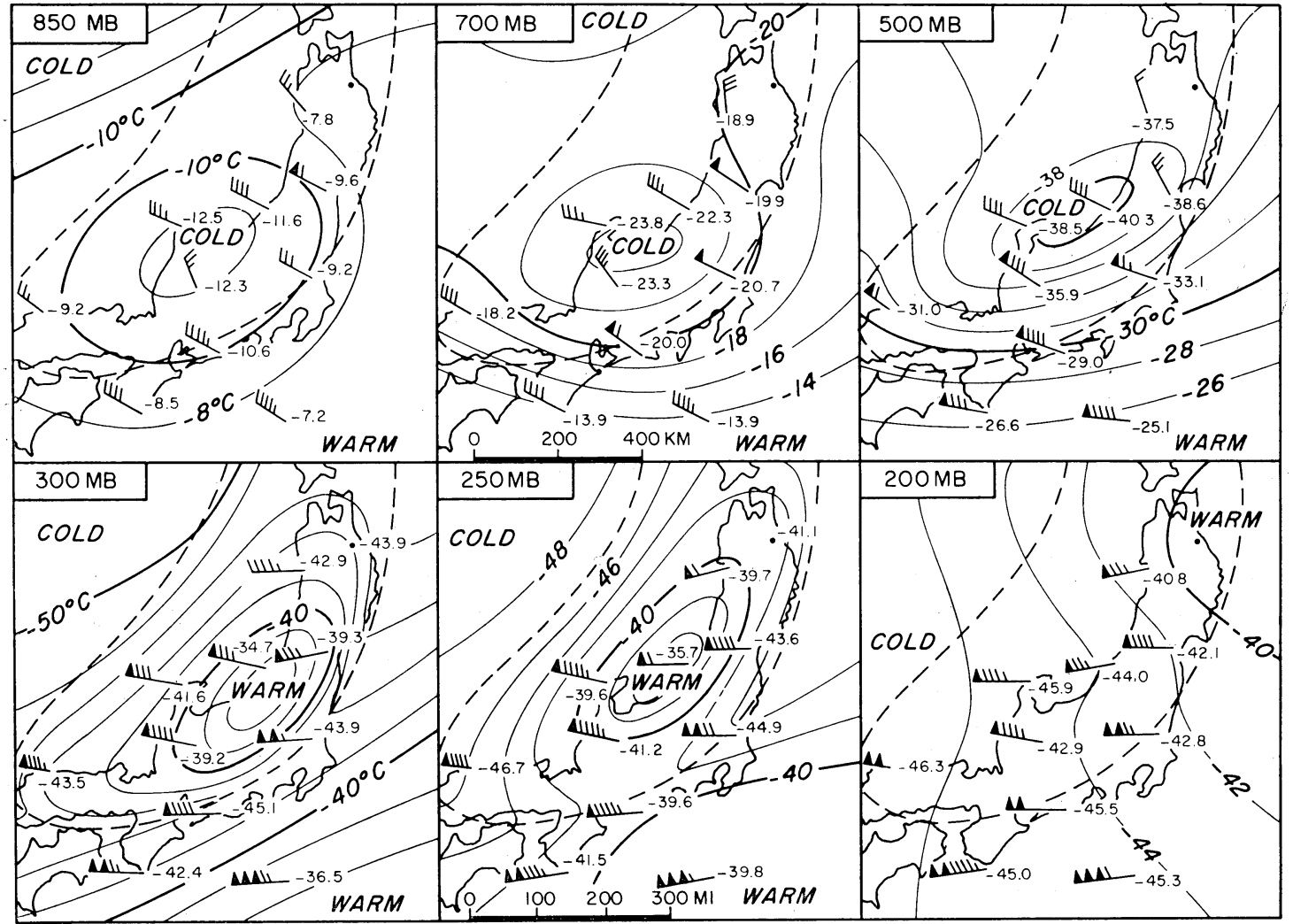

Fig. 6. Isotherms drawn on the 850-, 700-, 500-, 300-, 250- and 200-mb charts at 00Z, January $20,1964$. The region of monsoon snowfall is indicated by a dashed line. It should be noted that upper-air disturbances at various constant-pressure surfaces are more or less confined within the boundaries of the dashed lines. Note also that winds are not encircling either cold or warm cores; instead they are blowing through these cores within a few hours:

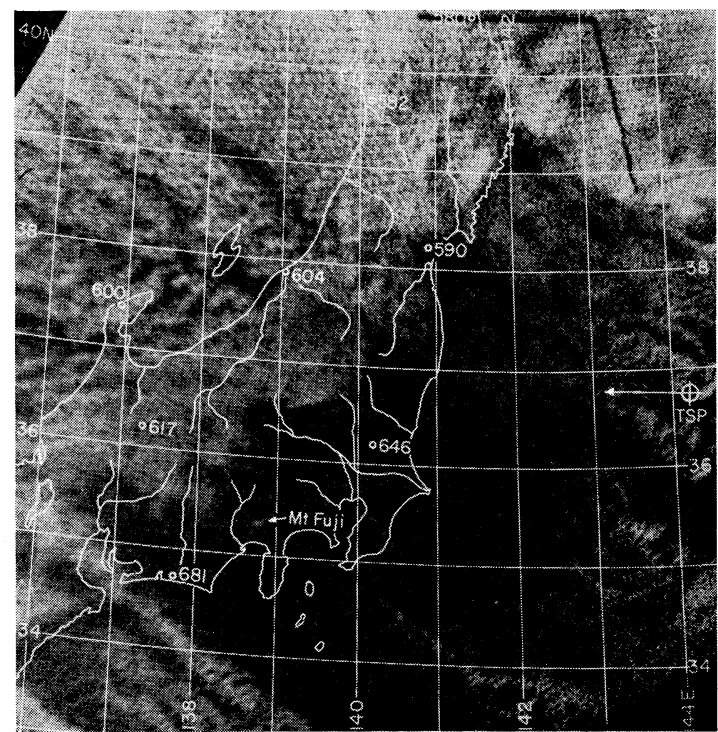

(1966). Detailed cloud and radiation patterns should be referred to in their paper; however, a satellite picture taken 20 min prior to the map time in Fig. 6 is presented in Fig. 7. The surface map of Fig. 3 shows an extensive area of snow along the Japan Sea side while the Pacific side is practically free from pre-

Fig. 7. A satellite photograph showing cloud patterns over Japan and its vicinity under the influence of the winter monsoon. A tape-mode photograph was rectified by the Fujita rectifier at the University of Chicago using photogrammetric data: Time $=2337.5 Z$, January 19, 1964 ; TSP Latitude $=36.7 \mathrm{~N}$; TSP Longitude $=144.2 \mathrm{E}$; Height $=639 \mathrm{~km}$; Tilt $=27.9 \mathrm{deg}$; and PrincipalLine Azimuth $=270.9 \mathrm{deg}$. The TSP appears to the right near the edge of the picture. Note that a snow-covered, 12, 395-ft volcano, Mt. Fuji, is visible as a small white spot indicated by an arrow. 
cipitation. Surface temperatures within the region of this monsoon snowfall are more or less uniform, ranging between -2 and $+2 \mathrm{C}$.

At the $850-\mathrm{mb}$ surface, however, a small cold area of $-12 \mathrm{C}$ is surrounded by a $-10 \mathrm{C}$ isotherm (Fig. 6). As the height increases, the cold area becomes more significant. A $-40 \mathrm{C}$ or colder area is seen at the $500-\mathrm{mb}$ surface, surrounded by an environment with temperatures ranging between $-31 \mathrm{C}$ and $-37 \mathrm{C}$, thus suggesting the vertical extent of the cold dome beyond this surface. When the height of such a mesoscale cold dome is compared with that of a much larger-scale cold dome such as studied by Matsumoto and Ninomiya (1965a), it will be found that their vertical extents are very similar to each other, though their horizontal dimensions are notably different.

The 400-mb chart, not reproduced herein, shows that the mesoscale cold dome disappears at about this surface, becoming a warm region as the height increases. The $300-\mathrm{mb}$ chart in Fig. 6 reveals a pronounced warm region directly over the low-level cold dome. This warm area extends upward beyond the $250-\mathrm{mb}$ surface, finally disappearing below the $200-\mathrm{mb}$ surface, at which no sign of warm area is visible.

A vertical cross-section was made in the direction of high-level winds through the disturbance (Fig. 8). The isentropes in the crosssection are drawn for every $2 \mathrm{~K}$, and the surfaces of discontinuity are shown by a series of small open circles. Both $\mathrm{A}$ and $\mathrm{B}$ denote the top of a modified cold air mass characterized by either moist- or dry-adiabatic stratification caused by heating and supply of moisture from the sea surface.

As a result of the existence of a cold area

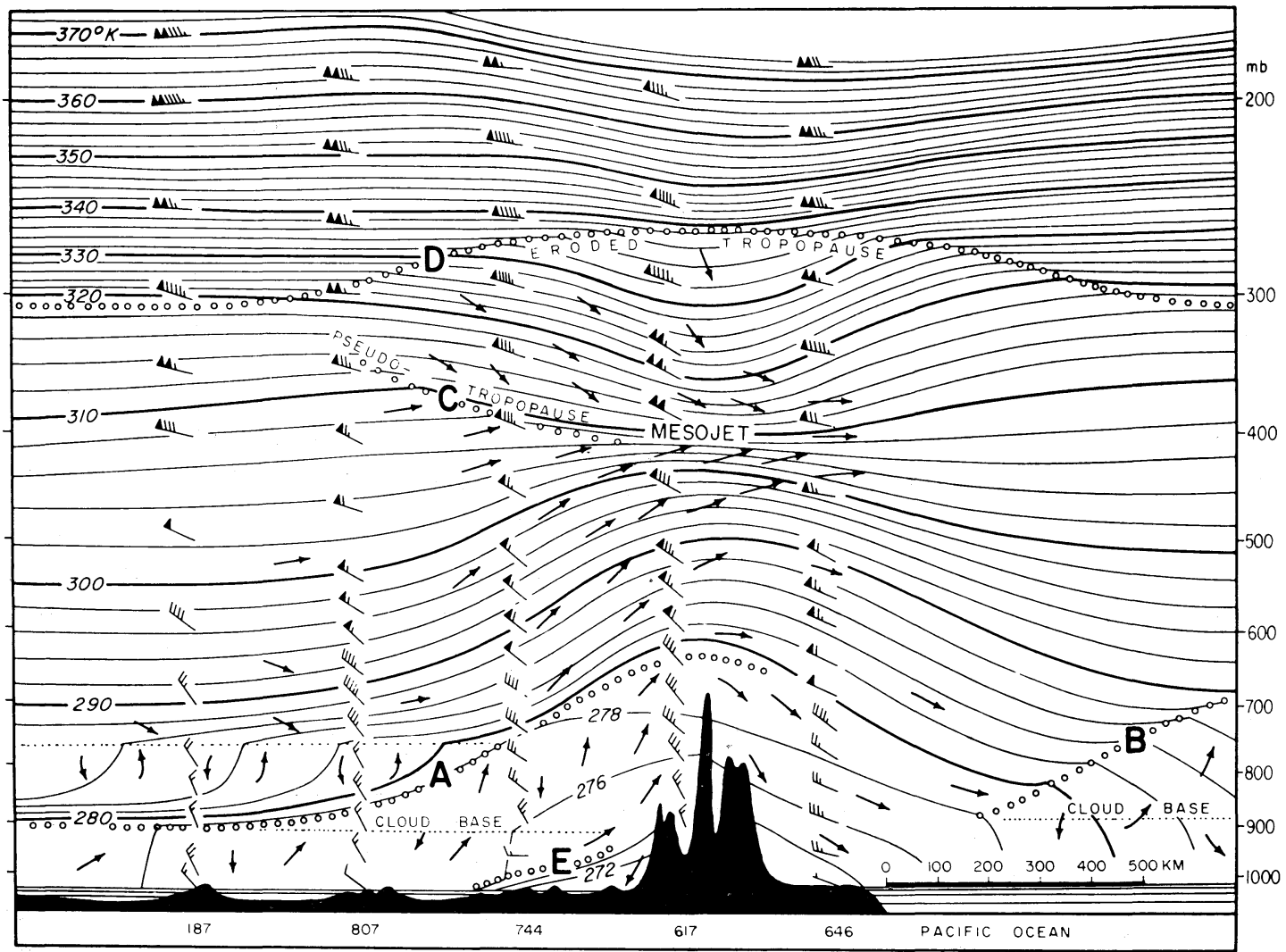

Fig. 8. A WSW-ENE cross-section through Mosulpo (187), Fukuoka (807), Yonago (744), Takyama (617) and Tateno (646). Arrows show schematical circulation inside the vertical plane. A nozzlelike configuration of isentropic surfaces of $300 \mathrm{~K}$ and $310 \mathrm{~K}$ is seen at about the $400 . \mathrm{mb}$ surface. An eroded tropopause and a pseudo-tropopause are the important features associated with the snowstorm mesojet. 
at low and middle levels and of a warm area at higher levels, the cross-section shows that the isentropes form a nozzle-like configuration at about $400 \mathrm{mb}$. If the flow through this nozzle is quasi-isentropic, a mechanical jet will appear as indicated in the figure. Due to thermal winds and the curvature of the quasiisentropic flow, maximum wind speeds are not observed at the height of this mechanical jet. Over Takayama (617), for instance, an increase in wind speed is seen even beyond the jet level, suggesting the existence of either thermal winds or reduction of the radius of curvature with increasing altitude. This type of jet stream occurring over the region of monsoon snowfall is rather short in the direction of the flow but it could be wide along the long axis of the snowfall region. The vertical extent of the jet stream is considerably thinner than that of a polar jet as described by Riehl et al (1954). The jet stream under discussion is much weaker in intensity as compared with a polar jet stream. In order to distinguish it from the other, while emphasizing its cause and dimensions, it will be called the "snowstorm mesojet".

Because a snowfall mesojet is characterized by a weak perturbation superimposed upon large-scale wind variations inside the troposphere, it can be shown convincingly on such wind profiles as presented in Fig. 9. The

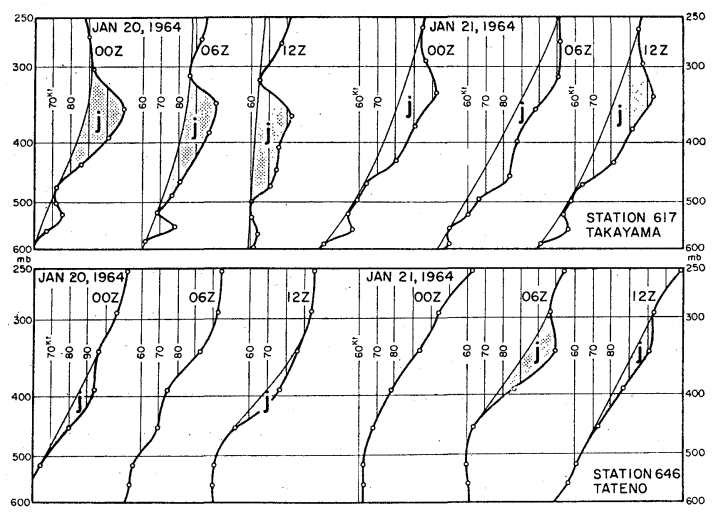

Fig. 9. Profiles of wind speed associated with the snowstorm mesojet over Takayama (617), in the upper diagram, and Tateno (646), which are located respectively, near the center and on the eastern boundary of a region of monsoon snowfall. Stippled areas designate the increment of wind speeds due to the mesojet. Note that winds over Tateno (646) are practically free from the influence of the mesojet. upper profiles are from Takayama (617), located near the center of the jet (see also Fig. 8). The windspeed increment due to the snowstorm mesojet " $\mathrm{j}$ " is emphasized by stippled areas existing between the $300-$ and $500-\mathrm{mb}$ surfaces. The rawin data from Niigata (604) revealed the existence of a similar mesojet. Tateno (646), located about $300 \mathrm{~km}$ downwind from Takayama (617), shows evidence of a very weak mesojet because the station is located beyond the eastern edge of the disturbance.

Returning to Fig. 8 , we see that the tropopause above the snowstorm mesojet is eroded, due probably to the descending motion of the lowermost stratospheric air drawn into the mesojet. A lifting of isentropic surfaces, initially accomplished by the moist convection of the modified polar air, will also be stimulated by the mesojet as it draws environmental air from the lower as well as the higher levels. Such a motion of the atmosphere in a vertical plane, shown in Fig. 8, will help maintain the mesojet which, in turn, produces a downward motion above and an upward motion below, thus stimulating more snowfall beneath the mesojet. The circulation as a whole results in a feedback system in which the intensification of the mesojet, the continuation of heavy monsoon snowfall, and the successive drainage of lower stratospheric air are interlinked.

It should be noted, however, that this represents indirect circulation in the entrance region of the mesojet, where warm air descends while cold air ascends. Through a process of indirect circulation, potential energy is always produced. The law of the conservation of energy states that the production of potential energy is identical to the loss of kinetic energy if the process is adiabatic and reversible. In other words, most of the indirect circulation involving a snowstorm mesojet is not energy-producing except for the latent-heat release inside the layer of moist convection. The mesoscale field of potential energy created by the lowering of the isentropic surfaces above the mesojet and the moundshaped lifting of the surfaces below comes from the kinetic energy of the strong northwest to westerly winds prevailing above the low-level dry cold air from Siberia, which is being modified by the warm surface of the 


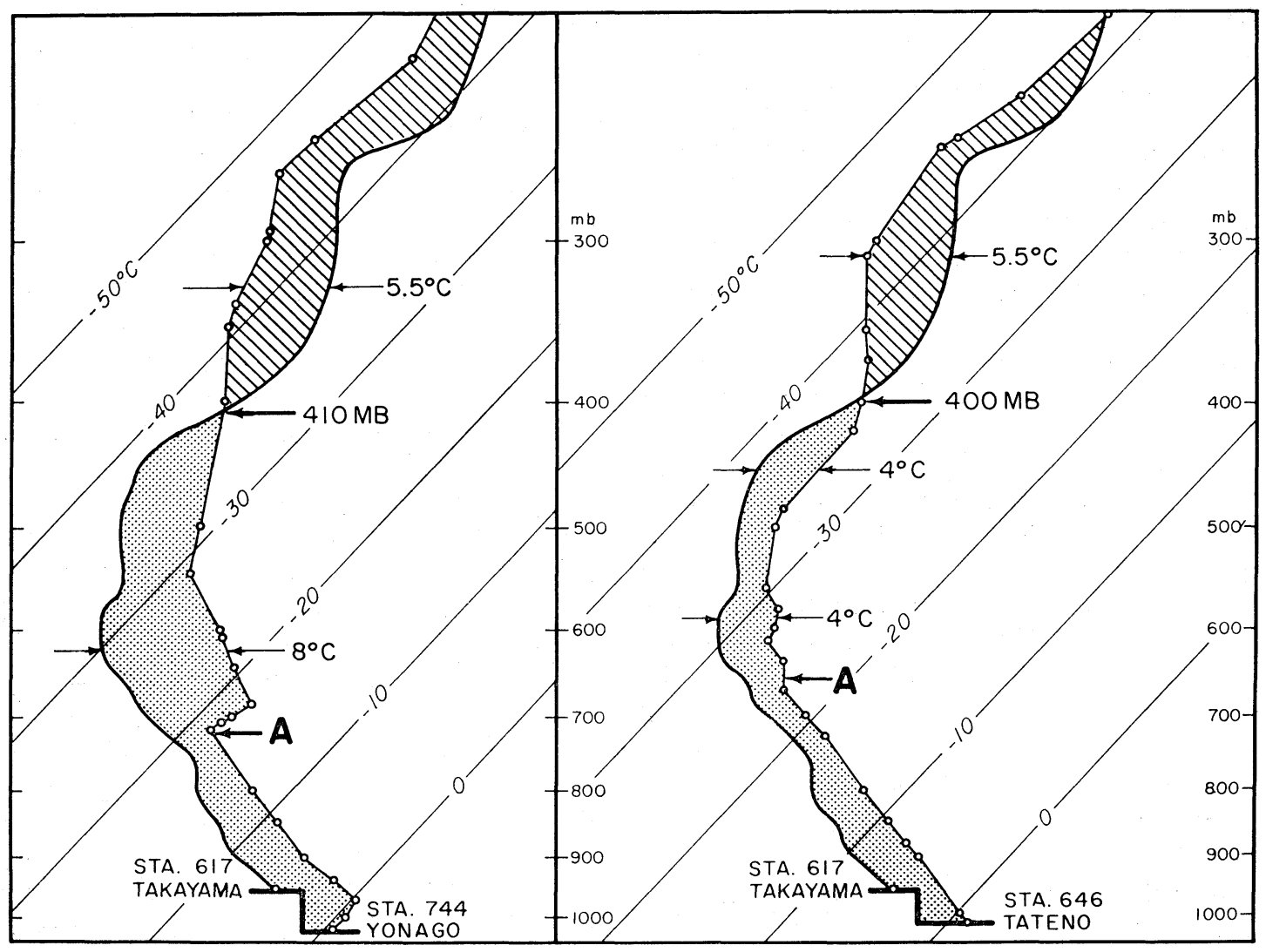

Fig. 10. The warm area above and the cold area below $400 \mathrm{mb}$ over Takayama (617).

Sea of Japan.

A vertical distribution of the temperature over Takayama (617) at 00Z, January 20, 1964 is shown in Fig. 10 where the soundings from Yonago (744), $350 \mathrm{~km}$ upwind, and from Tateno (646), $270 \mathrm{~km}$ downwind, are entered as references. Hatched and stippled areas represent, respectively, the positive and negative temperature anomalies accompanied by the mesoscale upper-air disturbance over the region of monsoon snowfall.

For the purpose of describing modification of the polar air mass as it travels over the Sea of Japan, the Japanese Islands, and the Pacific Ocean, a vertical cross-section (Fig. 11) was made along a streamline of low-level flow extending from Vladivostok (960) to Iwojima (115). Below the top of moist convection A and $B$, the temperature lapse rate should be that between dry and moist adiabats, depending upon the relative volume of clouds inside the modified air mass. The lapse rate in the subcloud atmospere is usually very close to dry adiabatic, causing the isentropes beneath the cloud base to be more or less vertical.

As a result of the forced lifting of surfaces $A$ and $B$, caused by the release of latent heat and partially by orography, they are topped by a stable layer (refer also to Fig. 10) in which the wind speed increases along the vertical because of only slight mixing through the stable layer. Quasi-isentropic flow over and above the moist-convection layer $\mathrm{A}$ drops the isentropic surfaces sharply toward the south, resulting in a pronounced baroclinic field accompanied by strong thermal winds. This would create a steep northward drop in the isobaric surfaces through the mesojet region. The primary drop, associated with a polar jet stream, and this secondary one are presented in Fig. 12. It should be mentioned that the secondary drop might have been overlooked had there been no special observations from Takayama (617) and Hamamatsu (681). In 


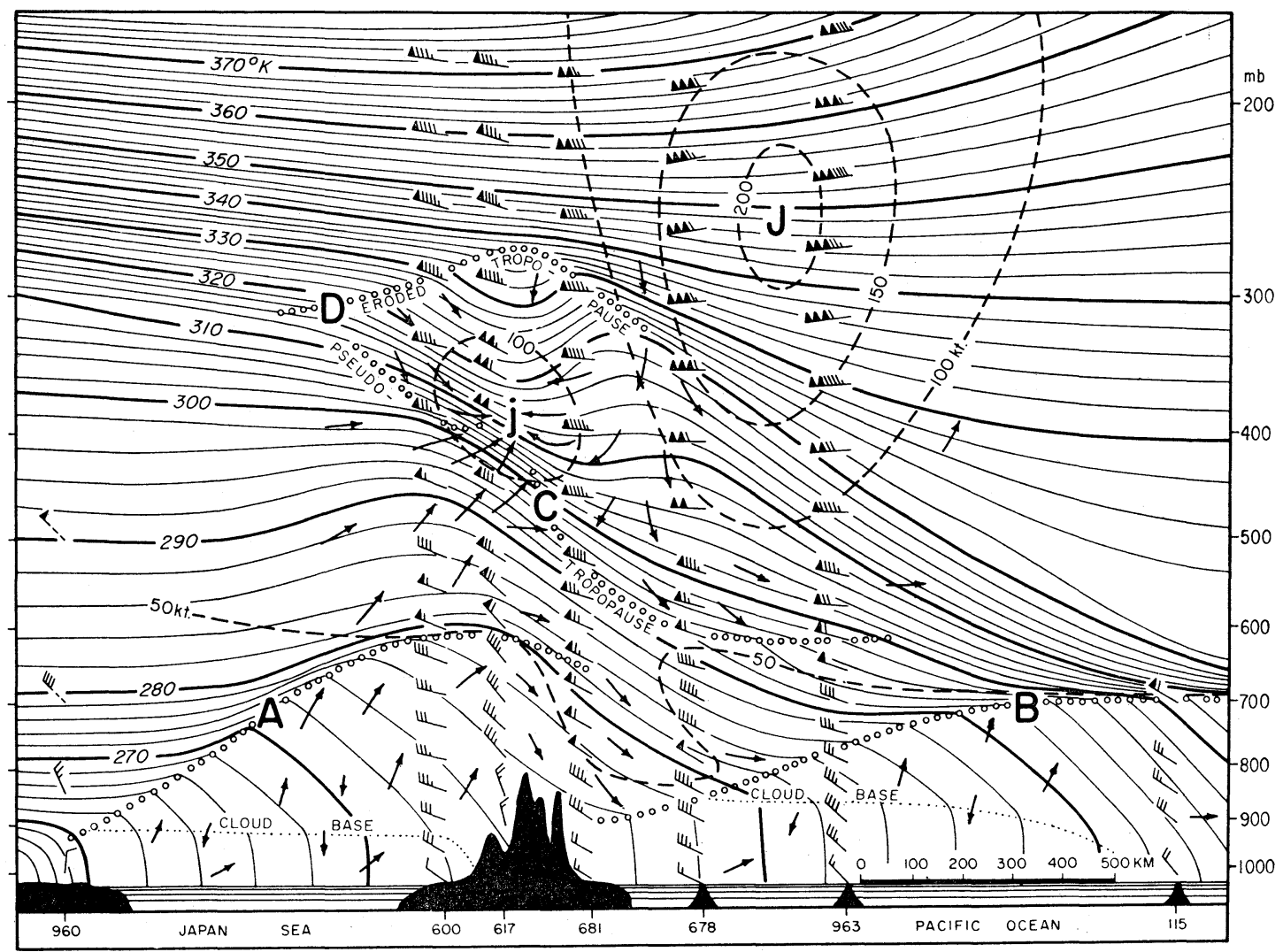

Fig. 11. Vertical cross-section along a low-level flow extending from Vladivostok (960) to Iwojima (115) by way of Wajima (600), Takayama (617), Hamamatsu (681), Hachijojima (678), and Torishima 963). An eroded tropopause directly above the mesojet and a pseudo-tropopause sloping down toward the south are the most interesting features. The pseudo-tropopause, in particular, which is characterized by an inversion or stable layer, has often been misinterpreted as the boundary vertically separating an old cold-air outbreak from a new one just entering over the Pacific Ocean.

fact, Takayama (617) was located where the gradient of the isobaric surface due to the secondary drop was largest. Without windaloft observations from this station, the mesojet appearing in Figs. 11 and 12 could not have been identified.

\section{Meridional circulation}

Since monsoon snowfall in Japan takes place after the outbreak of dry cold air from Siberia, a polar jet stream associated with the outbreak is usually located either over or south of the islands of Japan. The meridional circulation of a snowstorm mesojet is naturally affected by that of the polar jet stream, which is normally very strong and persistent.

As in usual cases of winter monsoon snow- fall, the polar jet stream at $00 Z$, January 20 , 1964 was located off the Pacific coast of Japan between Hachijojima (678) and Torishima (693). The area of analysis is influenced by the socalled entrance region - the region of confluence on the upwind side of a jet stream-in which subgradient winds are predominant.

In his early study of a three-dimensional process, Newton (1954) stated: “Although there may be some degree of unbalance between thermal and actual wind fields, in general there is fairly close agreement at any given time." Since that time, suspicion has been raised as to what degree winds in jet streams are in balance with the pressure field. Due to the difficulties involved in the accurate determination of both pressure gradient and the 


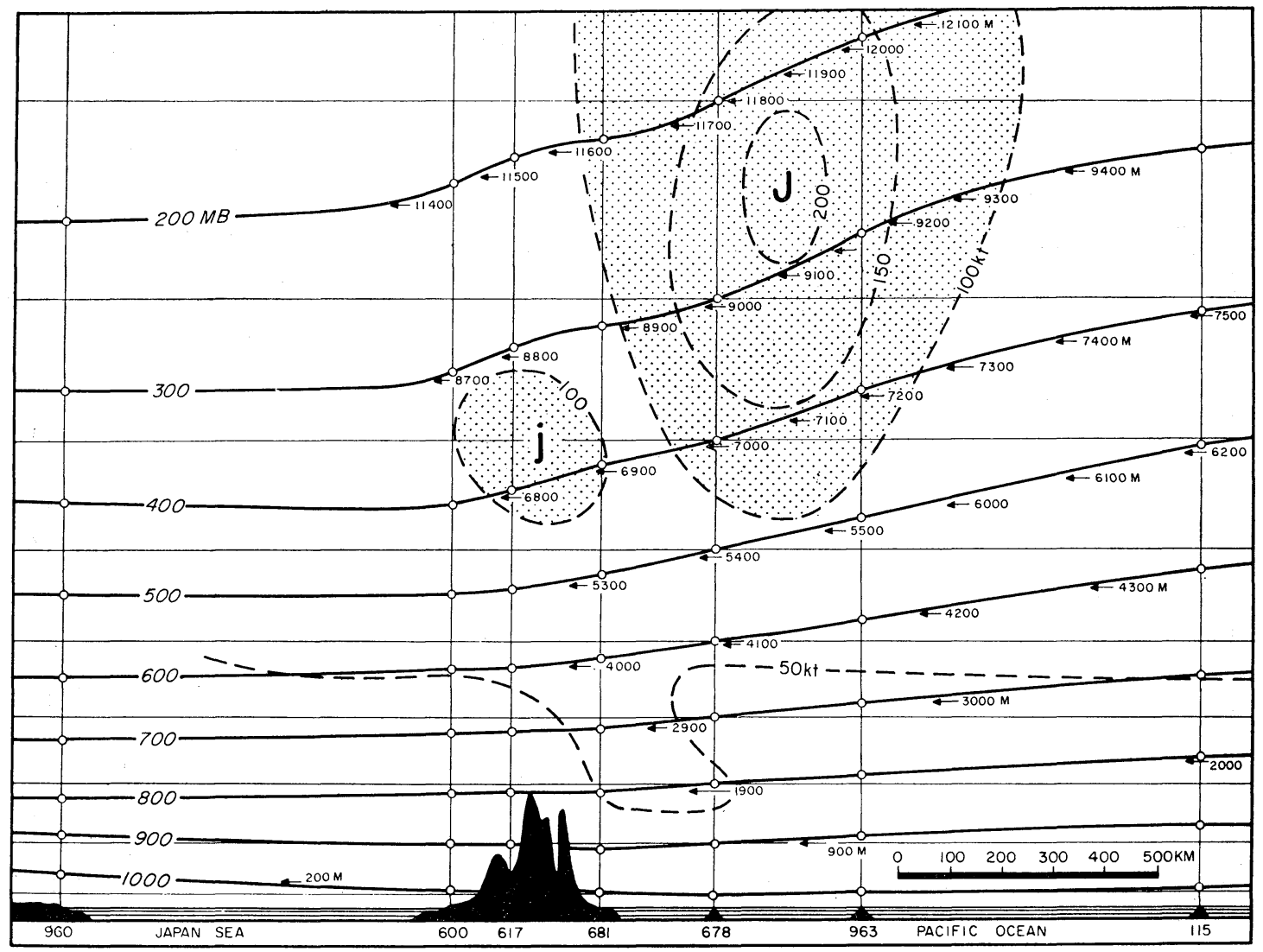

Fig. 12. Profiles of the constant-pressure surfaces at $100-\mathrm{mb}$ intervals.

curvature of high-level flow, the deviation of actual wind from either geostrophic or gradient wind is very hard to determine. Neiburger and Angell (1956) obtained some evidence of inertial oscillation by using constant-pressure balloons flown at the $300-\mathrm{mb}$ surface. Newton (1959) later calculated the inertial oscillation of winds, based upon the assumption that the acceleration of geostrophic and ageostrophic winds at the core of the strongest winds is identical.

It is now commonly agreed that the entrance region is characterized by subgeostrophic (or subgradient) winds, while the exit region is characterized by supergeostrophic (or supergradient) winds, thus creating divergence in the forward left and the rear right sectors and convergence in the forward right and the rear left sectors of a steady-state jet stream. An identical distribution of divergence and convergence fields can also be explained by the advection of absolute vorticity with its positive center to the left and its negative center to the right of the core of the strongest winds.

As expected from the above discussion, the entrance region of the jet stream at $00 Z$, January 20 was characterized by subgradient winds. The actual winds shown in the $350-\mathrm{mb}$ chart in Fig. 13 were weaker than the gradient winds computed from the height-contour intervals and the curvature. In view of the uncertainties involved in such calculations, one may doubt the results. Nevertheless, both the basic theory and the significant differences between the observed and calculated winds support the existence of subgradient winds.

The lower chart of Fig. 13 reveals the 600$\mathrm{mb}$ height contours in full lines and the thickness contours between the $350-$ and $600-\mathrm{mb}$ surfaces in dashed lines. A pronounced baroclinic field along the Pacific coast of Japan was produced by quasi-adiabatic warming as the air between these constant-pressure surfaces descended toward the Pacific Ocean. 

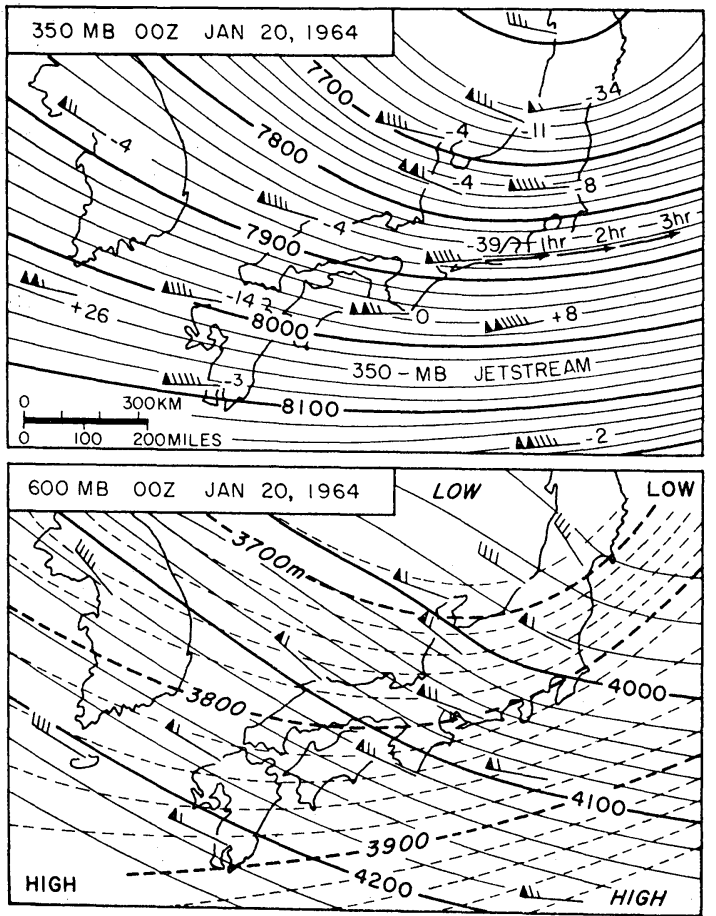

Fig. 13. A $350-\mathrm{mb}$ chart (upper) including $V-V_{\cdot r}$, the difference between the actual and gradient wind speeds, and a 600-mb chart with 350 - and $600-\mathrm{mb}$ thickness contours drawn with dashed lines. Three arrows running downwind from Hamamatsu (681) in the upper chart indicate the movement of the air during 1-, 2- and 3-hr periods. An inertial oscillation due to ageostrophic winds accompanied by a mesojet is of minor importance since the air moves out from the island within a very short time.

Even with the reduction of the radius of curvature when the thickness is added to the height of the lower constant-pressure surface, the gradient winds were accelerated from the Japan Sea side to the Pacific Ocean side of Japan, resulting in the increase of kinetic energy. Thus the loss of kinetic energy due to the indirect circulation discussed in the previous section will be compensated to a certain extent.

We shall now establish a model of meridional circulation around a snowstorm mesojet. Under the reasonable assumption that the mesojet is located in the entrance region of a polar jet stream south of Japan, the fields of divergence and convergence are placed as indicated in Fig. 14. Since a mesojet is characterized by subgradient winds, due to the fact that winds are being accelerated through a

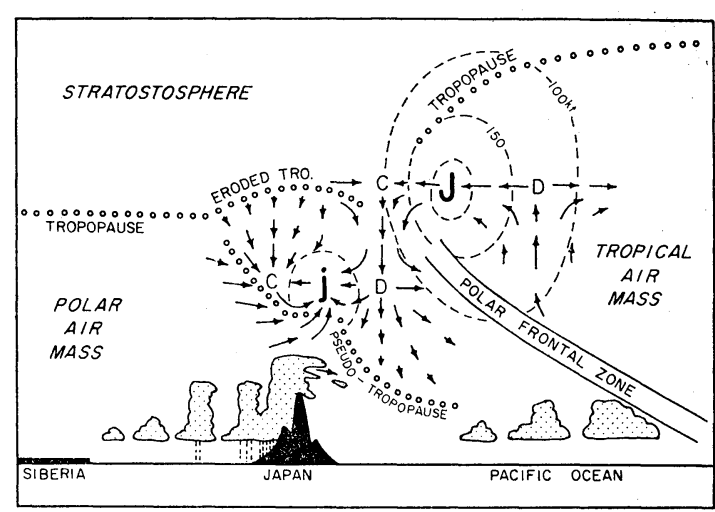

Fig. 14. Schematical meridional circulation involving a snowstorm mesojet located within an entrance region of a polar jet stream.

mechanical nozzle in analogy, the characteristics of the wind fields are similar to those in the entrance region of a polar jet stream. Thus we place both convergence and divergence at respective locations. Keeping in mind
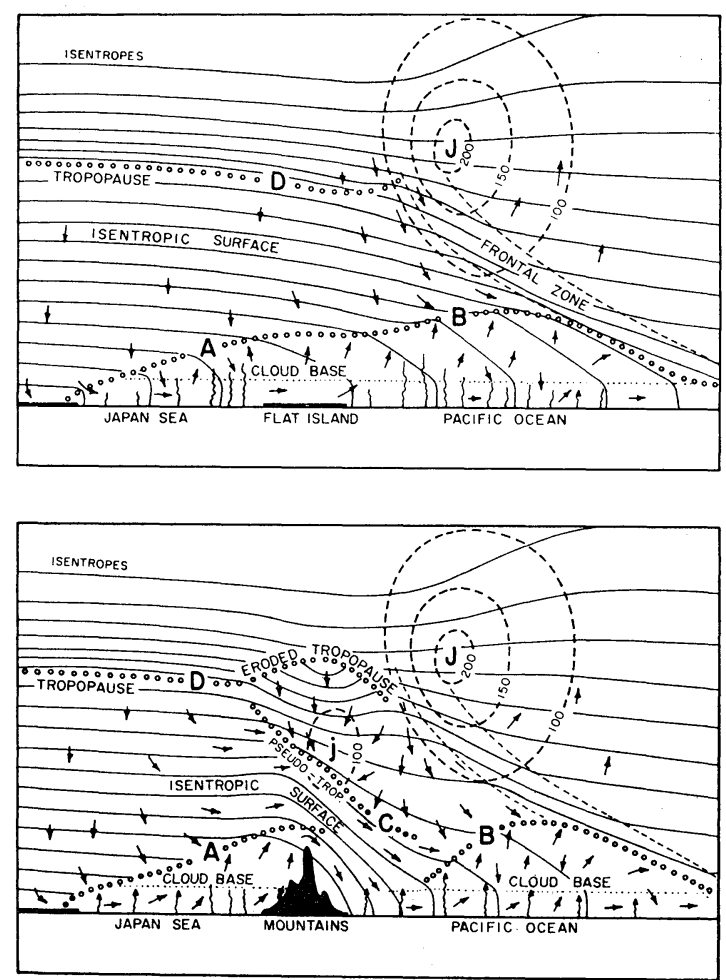

Fig. 15. Vertical cross-sections made along the direction of the low-level monsoon flow to show the influence of the Japanese Islands. The upper cross-section represents a hypothetical situation in which the topography of Japan would be flat; the lower cross-section, the more realistic case. 
that descending motion increases upward or decreases downward in a divergent field, the model circulation in the figure can be established. Such a motion of the atmosphere in the vertical plane will create a stable layer beneath the mesojet. This layer, which may be called a "pseudo-tropopause", is often reported as a tropopause at a very low height. The real tropopause above the mesojet is eroded by the subsidence toward the mesojet, thus resulting in a slightly higher but insignificant tropopause above the mesojet.

A generalized model of winter monsoon circulation in hypothetical situations where the islands of Japan are (1) flat and (2) mountainous appears in Fig. 15. This circulation model is self-explanatory in view of previous discussion.

\section{Analysis of 1963 data}

Results of the 1964 data analysis leading to the finding of the snowstorm mesojet over the region of monsoon snowfall convincingly support the existence of a low-level cold area accompanied by a high-level warm area. It is therefore to be expected that similar meso- scale upper-air disturbances would be seen in other years if special project data were available.

Upper-air data from Takayama (617) and Niigata (604) were taken during a special observation period, January $16-25,1963$. In order to visualize both cold and warm areas over the snowfall region in which these stations are located, temperature anomalies

$$
T_{617}-\frac{1}{2}\left(T_{600}+T_{681}\right) \text { for Takayama }
$$

and

$$
T_{604}-\frac{1}{2}\left(T_{600}+T_{646}\right) \text { for Niigata (604) }
$$

were computed and entered on Figs. 16 and 17 , respectively. At the top of each figure are also included the sea-level pressure and the hourly precipitation. Over these stations a persistent warm area approximately above the $400-\mathrm{mb}$ surface is visible, especially the temperature anomaly over Niigata (604) on January 18, which reached over $8 \mathrm{C}$. The lowlevel cooling was also persistent. Reported tropopauses are shown in the figures by black

\section{7, TAKAYAMA JANUARY, 1963}

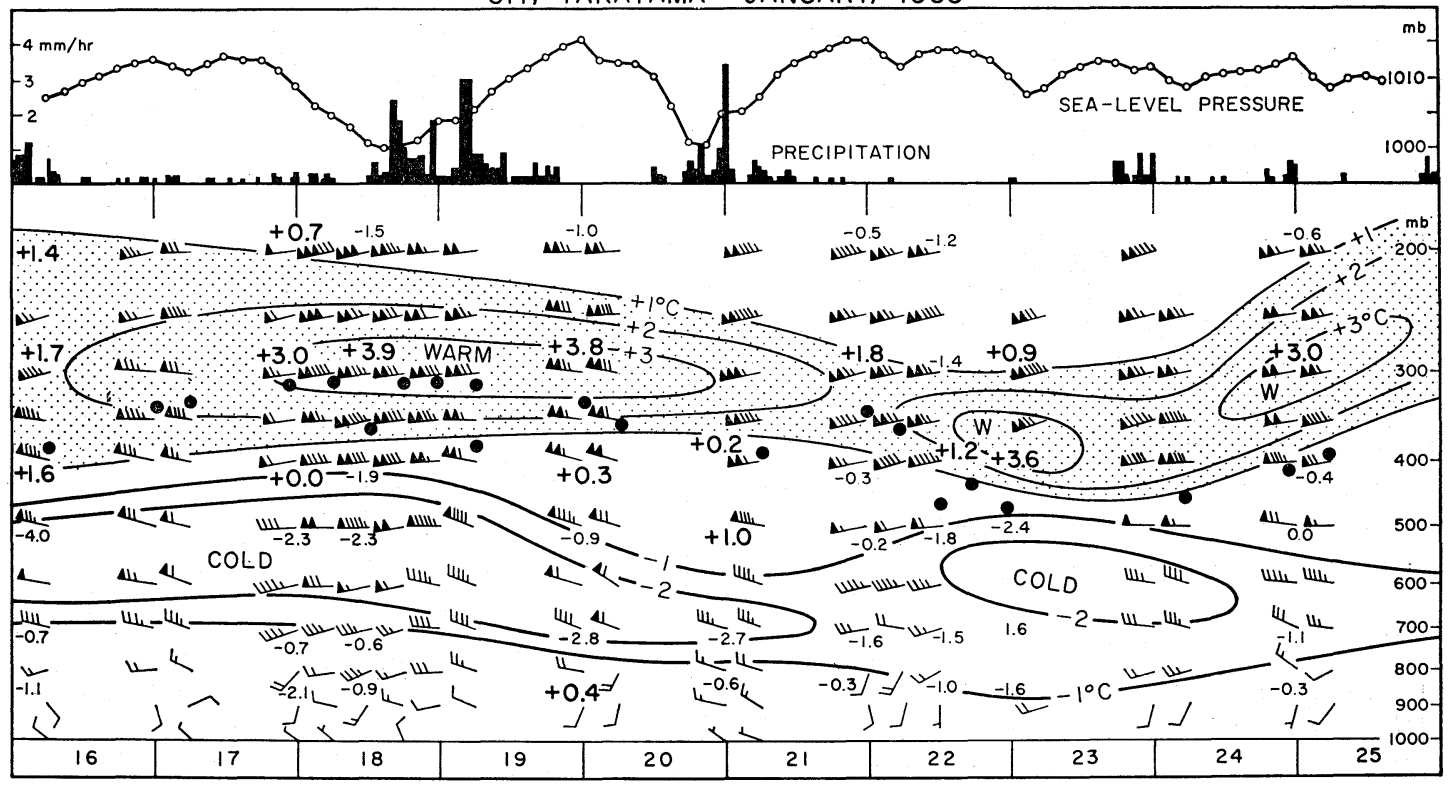

Fig. 16. The high-level warm and the low-level cold areas over Takayama (617), located near the center of the mesoscale upper-air disturbance. Both positive and negative numbers are the observed upper-air temperatures less the mean values of the temperatures over Wajima (600) and Hamamatsu (681), located, respectively, to the north and to the south and less affected by the mesoscale upper-air disturbance. Note that the warm area exists approximately above the 400mb surface. Black circles represent reported tropopauses or, more correctly, pseudo-tropopauses. 
604, NIIGATA JANUARY, 1963

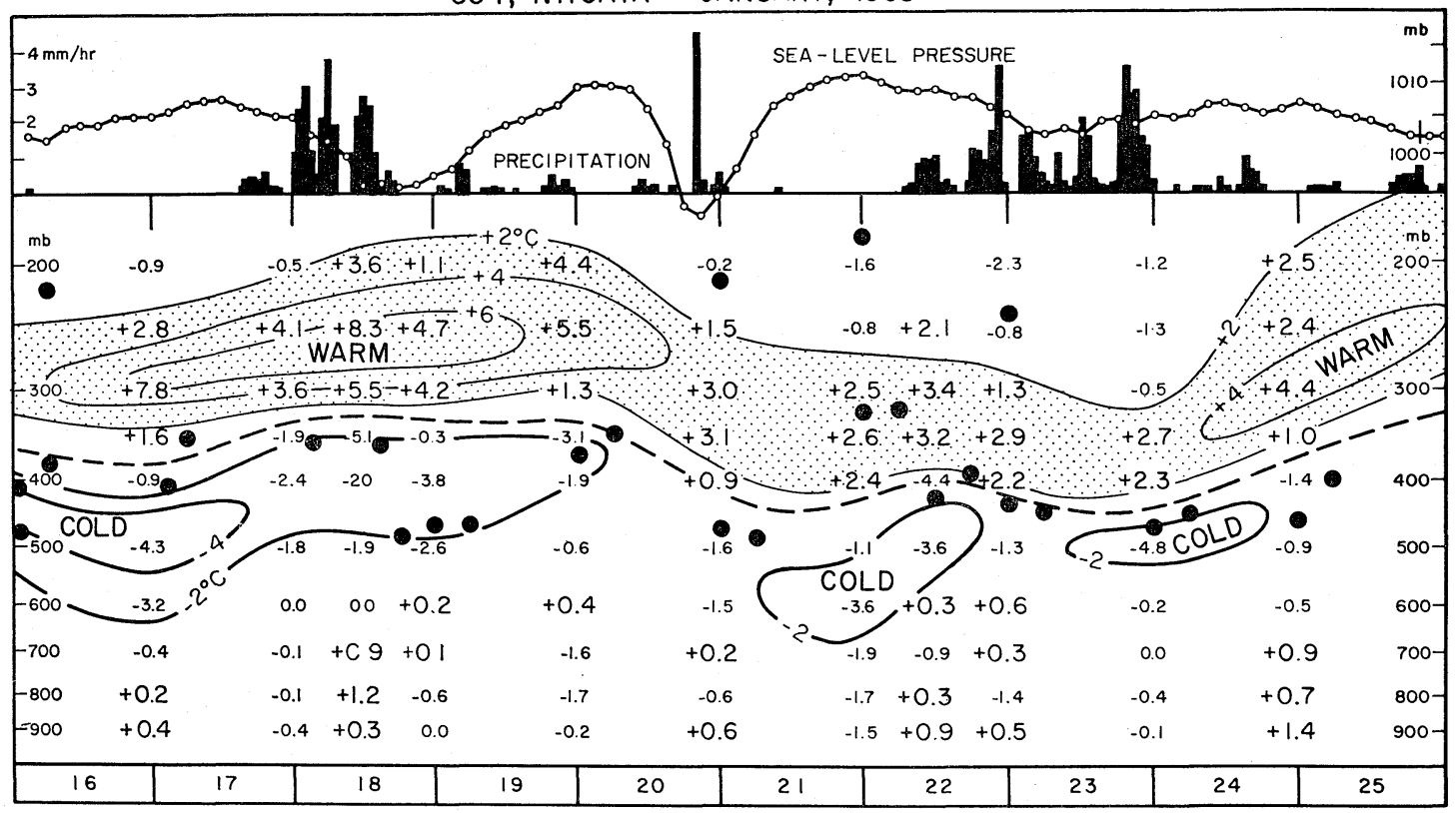

Fig. 17. The high-level warm and the low-level cold areas over Niigata (604) as revealed by the deviation of the upper-air temperatures from the mean temperatures from Wajima (600) and Sendai (580), located, respectively, to the west and to the east and less affected by the mesoscale upper-air disturbance. Black circles represent reported tropopauses, most of which should be interpreted as pseudo-tropopauses.

circles scattered near the height at which the low-level cold area changes into a high-level warm area. Most of these tropopauses represent the base of the subsidence accompanied by the snowstorm mesojet which had been in existence over the region of monsoon snowfall, and they represent pseudo-tropopauses.

\section{Conclusions}

Through this study of mesoscale upper-air disturbance, the existence of a mesoscale cold area topped by a pronounced warm area over the region of monsoon snowfall was confirmed. Both warm and cold disturbances remain over the snowfall regions, permitting the atmosphere to flow through the disturbances through semiadiabatic processes. A mesoscale jet is thus created, due to a nozzle-like configuration of isentropic surfaces in a vertical plane parallel to the flow. This jet, called a "snowstorm mesojet" in this paper, is maintained by a three-dimensional feedback system which procures energy from the general circulation of strong west to northwesterly winds as well as from circulation acceleration involving pronounced solenoids along the Pacific coast of the Japanese Islands.

It seems that the disturbances associated with the monsoon snowfall along the Japan Sea side of the islands extend much beyond the height of the snow-cloud tops, up to the lowermost portion of the stratosphere. Analytical findings on mesoscale atmospheric circulation reported in this paper should stimulate expanded theoretical studies of monsoon snowfall. It is hoped that similar investigations will be made along the western coasts of other land masses affected by polar outbreaks.

\section{Acknowledgments}

The authors are grateful to the members of the Typhoon Research Laboratory, Meteorological Research Institute, Tokyo, who assisted in the collection and analysis of the surface and upper-air data over the western Pacific. Sincere appreciation is also expressed to Mr. Linwood F. Whitney, J. of the Meteorological Satellite Laboratory, Environmental Science Services Administration for his assistance in analyzing the satellite data and for his participation in discussions regarding the structure of the mesojet. 
This research has been sponsored under the U.S--Japan Cooperative Science Program by the U.S. National Science Foundation under Grant NSF GF-179 and by the Japan Society for the Promotion of Science under Grant GEO-4. The research leading to the finding of the snowstorm mesojet was co-sponsored by the Meteorological Satellite Laboratory, Environmental Science Services Administration under Grant Cwb WBG-34.

\section{References}

Fukuda, K., 1960: Heavy snow in Japan. J. Japanese Soc. of Snow and Ice, 22, 73-81.

Higuchi, K., 1962: The band structure of snowfall. J. meteor. Soc. Japan, 41, 53-70.

Matsumoto, S., and K. Ninomiya, 1965a: On the analysis of a cold vortex with steady eastward movement. Papers in Meteor. and Geophys. $16,1-8$.

1965: Mesoscale disturbance observed in the vicinity of a cold vortex center. Ibid., 16, 9-22.
Matsumoto, S., T. Asai, K. Ninomiya, M. Iida and M. Takeuchi, 1965: Behavior of the extraordinary cold vortex over the Far East coastal area observed during the period from 22 January to 24 January 1963. J. meteor. Soc. Japan, 43, $100-115$.

Neiburger, M.. and J.K. Angell. 1956: Meteorological applications of constantpressure balloon trajectories. J. meteor., 13, 166-194.

Newton. C.W., 1954: Frontogenesis and frontolysis as a three-dimensional process. Ibid.. 11, 449461.

- - 1959: Axial velocity streaks in the jet stream: ageostrophic inertial oscillations. Ibid., 16, 638-645.

Riehl, H., M.A. Alaka, C.L. Jordan, and R.J. Renard 1954: The jet stream, Meteorological Monographs, 2, No. 7. 100 pages.

Tsuchiya, K. and T. Fujita, 1966: Satellite meteorological study of evaporation and cloud formation over the western Pacific under the influence of the winter monsoon. SMRP Research Paper, 55. University of Chicago.

\title{
冬の季節風下の日本列島上空の豪雪メソジェットの機構
}

\author{
藤田哲也 上屋清 \\ シカゴ大学 気象方
}

気像衛星写真と放射データを使って，冬の季節風下の日本付近の雲のメゾスケールの特徵を調べていたときに，季 節風に対して障碍物として横たわっている北海道や本州の風上側の降雪域の上空に, メゾスケールのじょう乱のある ことが解析された。平均間隔が $200 \mathrm{~km}$ の比較的細かい高層観测組の観測資料壮より，このメジシステムの垂西持 造のメゾ・シノプティック解析をした。このシステムの特徵は, 寒気塊のすぐ上飞, 破壊された圈界面から下降した 暧気のあることである。1963 年と 1964 年のデーターの解析結果とよれば, 上層の風はこのメジシステムを数時間で 吹さ奴行くけれども, システム自体は季節風による降雪域の上空飞停滞している。この上空のメゾシステムの形 成と発達の説明飞あたって，“豪雪メゾジェット”といらメゾスケールのジェットストリームを提示する。 